\title{
VERVOLGONDERZOEK NAAR DE INTERPRETATIE VAN NON- VERBAAL GEDRAG BIJ DE BEOORDELING VAN ASIELAANVRAGEN
}

Hubert Korzilius en Dick Springorum, Katholieke Universiteit Nijmegen, Faculteit Letteren, afdeling Bedrijfscommunicatie; Center for Language Studies ${ }^{1}$

\section{Inleiding}

In een experimenteel onderzoek naar de beoordeling van het waarheidsgehalte van asielverhalen op basis van de interpretatie van non-verbaal gedrag is gebleken dat professionele beoordelaars daarin noch consistent, noch homogeen zijn (Korzilius \& Springorum, 1999). Maatschappelijk gezien is dit een verontrustende uitkomst. Maar twijfel aan de ecologische validiteit van dit onderzoek heeft geleid tot een voorstel voor verder onderzoek. Via een hardop-denk procedure willen we achterhalen welke betekenis professionele beoordelaars toekennen aan aspecten van het non-verbaal gedrag van asielzoekers, wanneer hun dat wordt gepresenteerd in combinatie met verbaal gedrag. Dan kan nauwkeuriger worden vastgesteld of - en in welke mate professionele beoordelaars bij hun beoordeling van asielaanvragen in deze interculturele interactiesituatie consistent en homogeen zijn.

\section{De betekenis van lichaamstaal in een gehoorsituatie}

In Korzilius \& Springorum (1999) (in het vervolg aangeduid als Studie 1) hebben we verslag uitgebracht van een onderzoek naar 'de betekenis van lichaamstaal in een gehoorsituatie'. Aanleiding voor dat onderzoek waren de volgende overwegingen.

1. Het behoort tot de gesprekshouding van degenen die bij de beoordeling van asielaanvragen betrokken zijn, dat zij die aanvragen kritisch bezien. Dat betekent dat zij de vluchtverhalen van asielzoekers niet voetstoots aannemen, en de asielaanvrager met een 'beroepsmatig wantrouwen' tegemoet treden. Net als in andere situaties waarin cliënten een verzoek indienen voor maatschappelijke bijstand zullen deze beoordelaars bij het aanhoren van asielverhalen op zoek gaan naar 'contra-indicaties', die een grond kunnen vormen voor afwijzing van de aanvraag.

2. Bij twijfel aan het realiteitsgehalte van de inhoud van vluchtverhalen zullen beoordelaars op zoek gaan naar indicatoren buiten de inhoud van het verhaal. Uit communicatie-onderzoek is bekend, dat gesprekspartners in situaties waarin de gespreksinhoud een bepaalde mate van ambiguiteit vertoont, hun aandacht richten op aspecten van non-verbaal gedrag: mimiek, waaronder in het bijzonder oogcontact of juist het vermijden van oogcontact (wegkijken), en op lichaamshouding ('zenuwachtige'

1 Met dank aan Marike Dirkx, die met haar doctoraalscriptie onze interesse in dit onderwerp heeft aangewakkerd. Ook dank aan Hanneke Houtkoop-Steenstra, Henk van Jaarsveld en Carel Jansen voor commentaar op een vorige versie van dit artikel. 
bewegingen, 'frunniken' aan haren en/of kleding, gaan verzitten, en dergelijke). Nonverbaal gedrag heeft hier een meta-communicatieve functie, omdat het aanwijzingen bevat over de interpretatie van het verbale gedrag.

3. Veel asielzoekers komen uit andere culturen. Het is bekend, dat er tussen culturen aanzienlijke verschillen kunnen bestaan in de betekenis die aan aspecten van nonverbaal gedrag worden toegekend. Zo wordt 'oogcontact' tijdens een gesprek in de ene cultuur positief gewaardeerd, terwijl het in een andere cultuur als zeer ongepast wordt ervaren. Vergelijkbare verschillen zijn er aan te wijzen bij bijvoorbeeld de interpretatie van glimlachen (Pennycook, 1985; Hurley, 1992; Kellerman, 1992; Vrij \& Winkel, 1991; Vrij, 1994).

Juist daarom waren wij benieuwd welke betekenis degenen die bij de beoordeling van asielaanvragen vanuit de Nederlandse cultuur betrokken zijn, aan het non-verbale gedrag van deze asielzoekers toekennen. Nauwkeuriger: we wilden nagaan of deze betrokkenen in het toekennen van betekenis aan aspecten van non-verbaal gedrag consistent en homogeen zijn. Geformuleerd in onderzoeksvragen: 'Kent een beoordelaar aan hetzelfde non-verbale gedrag van een asielzoeker bij een tweede beoordeling ook dezelfde betekenis toe?' en 'Kennen beoordelaars onderling aan non-verbaal gedrag dezelfde betekenis toe?' Immers, als zou blijken dat dit niet het geval is, ontstaat er maatschappelijk gesproken een tamelijk verontrustend beeld: non-verbale gedragingen van asielzoekers zouden dan voor de betrokken beoordelaars geen vaste betekenis hebben; en wanneer beoordelaars op die kennelijk variabele betekenis van non-verbaal gedrag afgaan, zouden ze dus tamelijk willekeurig te werk gaan, terwijl zij wellicht zelf menen dat bun oordeel gefundeerd is.

Het onderzoek was als volgt opgezet en uitgevoerd. We hadden een Liberiaanse acteur gevraagd een aantal 'scènes' te spelen, van elkaar onderscheiden door een diversiteit aan non-verbaal gedrag. Die scènes hebben we op videoband zonder geluid voorgelegd aan een aantal beoordelaars (ambtenaren van de Immigratie- en Naturalisatiedienst, IND) met de vraag te beoordelen of de persoon in kwestie - de als een mogelijke asielzoeker ten tonele gevoerde acteur - in die afzonderlijke scènes wel of niet de waarheid sprak. Enkele scènes hadden we tweemaal in de reeks opgenomen.

Bij de analyse van de scores bleken de beoordelaars in hun oordeel niet homogeen te zijn, en ook niet consistent. De beoordelaars verschillen in de betekenis die zij aan nonverbaal gedrag toekennen; en wanneer zij hetzelfde gedrag voor een tweede maal beoordelen, voorzien zij dat vaak van een andere interpretatie.

\section{Discussie}

Naar aanleiding van Studie 1 hebben we kritiek ontvangen en hebben we met diverse mensen contact gehad over het onderzoek. Daarnaast hebben we opnieuw het materiaal bekeken en zijn we verder gegaan met ander onderzoek naar en theorieën over nonverbaal gedrag. Tezamen kun je dit opvatten als een discussie met Studie 1. We hebben een en ander bijeengebracht en gecategoriseerd in drie onderwerpen. Het zijn achtereenvolgens: de gehanteerde methodologie en analyses, de reikwijdte van onze experimentele bevindingen en een theoretische verdieping. We bespreken nu deze drie onderwerpen om van daaruit te komen tot een programmatisch voorstel voor verder onderzoek op dit terrein. 


\subsection{Methodologie en analyse}

Op de in Studie 1 gehanteerde methodologie en analyses is een aantal kritiekpunten geformuleerd.

Een eerste punt van kritiek is de beschrijvende en niet een toetsende opzet van Studie 1. Daarbij gaat het met name om de, in beschrijvende termen, vaststelling van de mate van interbeoordelaarsbetrouwbaarheid en van de bepaling van de non-verbale gedragingen die indicatief zijn voor de oprechtheid dan wel onoprechtheid van het vluchtverhaal. We meenden dat een beschrijvende opzet voor dit toch relatief onontgonnen terrein op zijn plaats was. Met een aantal nieuwe analyses zijn we evenwel in staat om aan de geformuleerde kritiek tegemoet te komen. De interbeoordelaarsbetrouwbaarheid hebben we vastgesteld middels Fleiss' kappa (Fleiss, 1971; Rietveld \& Van Hout, 1993). Dit is een uitbreiding van de bekende maat kappa van Cohen voor situaties met meer dan twee beoordelaars. De door ons berekende maat geeft de mate van overeenkomst in de beoordeling van de fragmenten weer (zonder de herhaalde fragmenten). De waarde van Fleiss' kappa was .06 (bijbehorende Z-score $=6.18, \mathrm{p}<.0001$ ). Dat betekent dat er sprake is van een lage betrouwbaarheid. We zien een bevestiging van ons eerder beschreven resultaat: er is weinig overeenstemming in de interpretatiestrategieën na vertoning van de videofragmenten met non-verbaal gedrag.

$\mathrm{Om}$ te toetsen welke non-verbale gedragingen in de ogen van de beoordelaars indicatief zijn voor de onoprechtheid van het asielverhaal hebben we verschiltoetsen voor gecorreleerde proporties (Ferguson \& Takane, 1989) uitgevoerd voor alle (niet dubbel vertoonde) fragmenten. In essentie zijn dit toetsen voor herhaalde metingen. Paarsgewijze vergelijking van alle fragmenten levert 36 vergelijkingen op. Teneinde het statistische effect van het aantal vergelijkingen tegen te gaan, hebben we de Bonferroni procedure toegepast (Maxwell \& Delaney, 1990). Het significantieniveau komt daarmee op .05/36 $=.0014$, corresponderend met een Z-score van $\geq|3.18|$. Uit deze analyses komt naar voren dat men een aantal gedragingen als onoprecht beoordeelt in vergelijking met een als oprecht beschouwde 'uitdrukkingsloze pose'. Met name 'wegkijken' $(Z=3.21)$, 'zelfmanipulatie aan haren' $(Z=3.50)$, 'zelfmanipulatie aan kleren' $(Z=3.46)$ en 'glimlachen' $(Z=3.36)$ beoordeelt men in vergelijking hiermee als een indicatie voor onoprecht gedrag. Daarnaast blijkt dat men 'zelfmanipulatie aan haren' als onoprecht non-verbaal gedrag ziet in vergelijking met 'schouders ophalen' $(\mathrm{Z}=3.32)$. Met deze toetsende analyse nuanceren we de bevindingen van Studie 1. Het blijkt dat met name non-verbaal gedrag dat voor Nederlandse beoordelaars ongeïnteresseerdheid uitstraalt als indicatief voor onoprecht gedrag wordt gezien. Wij veronderstellen dat beoordelaars ongeïnteresseerdheid, het zich ten dele afsluiten van de interactiepartner, zien als een middel van de asielaanvrager om zich minder grijpbaar te maken voor de interactiepartner en daarmee als een mogelijke aanduiding van onoprechtheid van diens motieven (zie ook paragraaf 3.3 theoretische reflectie).

\subsection{De reikwijdte van de bevindingen van Studie 1}

Als kritiek is geformuleerd dat het achterwege laten van het verbaal gedrag in de in Studie 1 gehanteerde experimentele opzet een bedreiging vormt van de ecologische validiteit: daarmee wordt te ver afgeweken van de realiteit in een asielgehoor. Het verbale gedrag, de inhoud, vormt volgens deze kritiek een te belangrijk onderdeel om deze los te 
laten. Onze reactie hierop is dat we ons in Studie 1 met name op de metacommunicatieve aspecten van non-verbaal gedrag hebben gericht (zie boven). We hebben in deze opzet het verbale gedrag achterwege gelaten omdat het volgens ons dan waarschijnlijk het effect van het non-verbale gedrag zou hebben overstemd. Dat neemt niet weg dat we menen dat in vervolgonderzoek de verbale aspecten van het asielverhaal wel degelijk mee moeten worden genomen.

Een ander probleem bij Studie 1 is het volgende. Is het eigenlijk wel 'nieuws' dat er weinig overeenstemming is in de interpretatiestrategieën van beoordelaars die zich geconfronteerd zien met ambigue informatie: beoordelaars zullen immers betrekkelijk subjectieve oordelen over de informatie geven. Ons weerwoord hierop is: wie stelt vast wanneer informatie voor beoordelaars ambigu is? In Studie 1 ging het er nou juist om, dat door de wijze waarop beoordelaars de informatie interpreteren wordt aangetoond dat die informatie ambigu is, terwijl mogelijk in de reële gehoorsituatie wordt verondersteld dat die informatie er niet toe doet of een vanzelfsprekende niet-ambigue betekenis heeft.

Ook vanuit het maatschappelijke veld kwamen reacties. In Trouw (26 november 1997) meldt VluchtelingenWerk Nederland niet verbaasd te zijn over de uitkomsten van het onderzoek en wijt dit aan het ontbreken van training van IND-ambtenaren in de omgang met andere culturen, en "dat komt natuurlijk ook tot uitdrukking in de beoordeling van non-verbaal gedrag." Vanuit het IND wordt gesteld dat het opleidingsprogramma voor contactambtenaren inmiddels sterk is verbeterd. Wij menen dat we vanuit de taal- en communicatiewetenschap zo goed en helder mogelijk onderzoek dienen te verrichten naar de rol van non-verbaal gedrag bij de interpretatie en beoordeling van asielaanvragen en dat op basis hiervan betrokkenen zelf hun oordeel kunnen vormen.

\subsection{Theoretische reflectie}

In de literatuur wordt de invloed van non-verbaal gedrag op het verloop van menselijke communicatie niet betwist.

De bevindingen uit communicatieve studies zijn tamelijk eenduidig en sluiten aan bij de dagelijkse ervaring. Immers, de wijze waarop een gesprekspartner zich non-verbaal gedraagt - diens mimiek, zijn lichaamshouding en de gebaren die hij maakt, aanrakingsgedrag of juist het vermijden daarvan, de onderlinge afstand die hij in acht neemt - heeft onmiskenbaar invloed op het verloop van het gesprek en van de interactie die via dat gesprek gerealiseerd wordt (Koomen, 1988; Vrugt \& Schabracq, 1991).

Ook in indicatieve studies wordt gewezen op de betekenis van non-verbaal gedrag. Maar het beeld is hier gecompliceerder. Er is nogal wat psychologisch onderzoek verricht waarin men non-verbaal gedrag - vaak met inbegrip van non-verbale aspecten van taalgebruik als stemkwaliteit, spreeksnelheid, luidheid en intonatie - ziet als 'uiterlijke' indicator van 'innerlijke' gemoedstoestanden als emoties, gevoelens, attitudes, en van karaktereigenschappen en persoonlijkheidskenmerken. Bij de interpretatie daarvan hebben psychologen zich aanvankelijk een tamelijk grote mate van vrijheid veroorloofd, waarbij zij veronderstellingen vrij snel tot theorieën verhieven. Pas in de laatste drie decennia is sprake van een meer systematisch onderzoek (Vrugt \& Schabracq, 1991, 30 en verder).

Echter, juist onderzoek naar de relatie tussen non-verbaal gedrag en het verbergen of maskeren van de waarheid heeft betrekkelijk weinig houvast opgeleverd. Het globale beeld dat uit de literatuur naar voren komt, is het volgende. 
Bij misleiding spelen bepaalde gevoelens een rol, die zich manifesteren in bepaalde vormen van gedrag. Omdat misleiding in strijd is met heersende normen en waarden zou het gevoelens van schuld (de waarheid wordt immers verborgen) en angst (om te worden betrapt) oproepen. Mensen voelen zich bij misleiding dan ook niet op het gemak en proberen zich daarom minder 'grijpbaar' te maken voor de interactiepartners door weg te kijken, te glimlachen, en door veelvuldige zelfmanipulaties, om zich zo geheel of gedeeltelijk voor hen 'af te sluiten' (Vriij, 1991).

Een andere factor die bij misleiding een rol zou spelen, is controle. Om de waarheid te verbergen moeten mensen hun ware gevoelens en gedachten maskeren. De spanning die dit met zich mee brengt, zou zich uiten in een toename van lichaamsbewegingen. Om ontmaskering te voorkomen tracht men dan controle over zichzelf uit te oefenen, waardoor men echter juist een onnatuurlijke verstarde indruk maakt. Ekman e.a. (1991) stellen dat de meeste mensen hun gedrag zoveel mogelijk proberen te controleren wanneer zij belangrijke motieven hebben om te liegen en het vergaande consequenties heeft om te worden betrapt. Ekman e.a. (1991) veronderstellen dat naast de verbale inhoud, de spreeksnelheid en de vloeiendheid van de uitspraak juist de meeste lichaamsbewegingen en opvallende gezichtsuitdrukkingen meer bewust gecontroleerd kunnen worden dan toonhoogte en meer subtiele gezichtsuitdrukkingen. Het is dan ook te verwachten dat men, om onthulling te voorkomen, gaat overcompenseren op de bewust te controleren gedragingen. Kalma e.a. (1996) menen hiervoor inderdaad aanwijzingen gevonden te hebben.

Een derde psychologische factor die een rol zou spelen, is cognitie. Misleiden vereist een grotere cognitieve inspanning dan het vertellen van de waarheid, omdat moet worden opgelet of het gefingeerde verhaal consistent is en niet ingaat tegen de feiten die bij de tegenpartij bekend zijn. Daar gaat nogal wat energie in zitten; en daarom zullen non-verbale gedragingen zoals het maken van ondersteunende gebaren enigszins verwaarloosd worden. Misleiding zou daarom gepaard gaan met minder hand- en armgebaren (Vrij, 1991).

De onderzoeksprocedures en de gevonden resultaten laten echter nogal wat ruimte voor discussie (Ekman \& Friesen, 1974; Ekman, 1988; DePaulo, 1988; Vrij e.a., 1992; Vrij, 1992; 1994). Indien er al sprake is van betrouwbare inferenties, dan vereist een trefzekere detectie van onoprechtheid - zo leert de alledaagse ervaring en zo rapporteren ook onder andere Vrugt \& Schabracq (1991) - veel ervaring, die ondersteund kan worden door een serieuze training. Giesbers (1999) waarschuwt overigens dat onderricht in interculturele communicatie niet vanzelfsprekend leidt tot het kunnen omgaan met cultuurverschillen. Vaak wordt in training uitgegaan van een nogal statisch perspectief op cultuur (cultuur is te vatten als een leerbaar vaststaand cognitief gegeven, bijvoorbeeld een Aziaat kijkt je zelden rechtstreeks in de ogen). Het is beter om in training een dynamische visie uit te dragen: probeer greep te krijgen op het procesmatige karakter van cultuur en op de communicatieprocessen waarbinnen en waardoor mensen gestalte en uiting geven aan hun cultuur. In een onderzoek naar beurtwisselingspatronen in Turkse gezinnen in Nederland laat Huls (1995) bijvoorbeeld zien dat stereotype beelden over Turkse gezinsverhoudingen, met een veronderstelde hiërarchie van de autoritaire man (een statische visie), in communicatief opzicht zeer nadrukkelijk moet worden genuanceerd: macht in Turkse gezinnen blijkt geen exclusieve zaak van de man. Wie op zulke zaken in onderricht niet expliciet is gewezen, loopt een reële kans eerder door eigen 'theorieën' misleid te worden dan door het nonverbale gedrag van de betrokkene. 
Welnu, men mag veronderstellen dat de IND-ambtenaren die bij het gehoor betrokken zijn, zich bewust zijn van cultuurverschillen en van de rol die verschil in cultuur speelt bij de interpretatie van non-verbaal gedrag. Dit bewustzijn kan, minstens voor een deel, de voorzichtigheid verklaren waarmee zij in het eerdere onderzoek het non-verbale gedrag geïnterpreteerd hebben. (In Studie 1 bleek deze voorzichtigheid uit de 39\% van het non-verbaal gedrag dat wordt beoordeeld als 'twijfelachtig', 'weet niet' of met een 'restcategorie'.) Maar het is onwaarschijnlijk dat zij geschoold zouden zijn in de interpretatie van misleidend gedrag in deze interculturele interactiesituatie. Daar komt bij, dat het gehoor zich afspeelt in een triadische gesprekssituatie: asielzoekers vertellen hun verhaal immers in de regel aan een tolk, die het vertaalt voor de betrokken ambtenaar. Dat alles tezamen roept nieuwe, aanvullende onderzoeksvragen op met betrekking tot interpretatiestrategieën die de betrokken IND-ambtenaren hier hanteren: - Is het wel zo dat beoordelaars hun interpretatie van de waarheid van asielverhalen inderdaad baseren op aspecten van non-verbaal gedrag? En als dat zo is, welke rol speelt non-verbaal gedrag dan bij hun oordeelsvorming?

- Wanneer de interpretatie van non-verbaal gedrag bij hun oordeelsvorming een belangrijke rol blijkt te spelen, op welke aspecten van non-verbaal gedrag baseren zij dan hun oordeel? Is hier sprake van 'individuele' veronderstellingen of is hier een 'algemene lijn' te ontdekken?

4 Voorstel voor vervolgonderzoek naar non-verbale communicatie bij de beoordeling van asielaanvragen

\subsection{Interpretatiestrategieën}

De zojuist geformuleerde onderzoeksvragen zijn niet direct uit analyse van asielaanvraaggesprekken te beantwoorden: ook daarvoor is onderzoek vereist dat gericht is op analyse van het interpretatieproces. Het reële interpretatieproces kan benaderd worden via een 'hardopdenk'-procedure, waarbij meerdere beoordelaars een video-opname van een reëel asielgesprek becommentariëren. Deze methode werd al in het begin van deze eeuw toegepast, maar is pas op grotere schaal gebruikt in de jaren '80 (Breuker e.a., 1986; zie ook De Jong \& Schellens, 1995). De essentie van deze methode is dat deelnemers, wanneer zij bezig zijn met de oplossing van een probleem of met de uitvoering van een lastige taak, hun gedachten onder woorden brengen. De protocollen daarvan geven inzicht in de denkprocessen waarmee zij trachten het probleem op te lossen of de taak uit te voeren. Bekende toepassingen van deze methode zijn studies naar het denken van de schaker (De Groot, 1965); en studies naar de strategieën van studenten bij het schrijven van teksten. Analyse van de protocollen in deze laatste setting geeft inzicht in de problemen die schrijvers ervaren en in de strategieën die zij hanteren om deze problemen op te lossen (Flower, 1989; Hayes \& Flower, 1983); en een aanzienlijk betrouwbaarder inzicht dan wanneer van schrijvers gevraagd wordt hun strategieën achteraf, na voltooiing van hun taken, onder woorden te brengen (zie Nisbett \& Wilson, 1977; zie ook Ericsson \& Simon, 1980 en 1993). 


\subsection{Onderzoeksdesign}

Het beoogde onderzoek kan als volgt worden uitgevoerd.

1. Er worden video-opnames gemaakt van een aantal asielgesprekken. Daarvan worden er twee geselecteerd, waarin het asielverhaal naar het oordeel van de INDmedewerker die het gesprek gevoerd heeft, discutabel is.

De asielaanvrager moet zo duidelijk mogelijk en face in beeld worden gebracht, zodat diens bovenlichaam, gezicht en handen goed zichtbaar zijn. Maar de opname moet zo worden gearrangeerd en eventueel zodanig worden toegelicht, dat de deelnemers het opnemen van het gesprek op videoband niet als bedreigend ervaren, en het asielgesprek z'n normale verloop kan hebben. Eventueel kan een verborgen camera worden gebruikt.

2. De exploratieve aard van het onderzoek brengt met zich mee, dat de protocollen allereerst gesegmenteerd moeten worden op basis van relevante stappen in het probleemoplossingsproces. Dat betekent dat er een coderingsschema ontwikkeld moet worden, dat aangeeft welke verbale uitingen van de beoordelaars - in combinatie met de vertalingen van de tolk - als representatie van een veronderstelde interpretatie gezien moeten of kunnen worden (zie onder andere de suggesties in Janssens, 1988). Aangezien er nog geen operationaliseerbare theorie voorhanden is, worden het coderingsschema en de theorie in een cyclisch proces geconstrueerd (zie Breuker e.a., 1986, p. 247).

De protocollen worden aldus gesegmenteerd in 'interpretatieketens': gespreksdelen waarin aspecten van het asielverhaal geïnterpreteerd worden in de richting van een mogelijke probleemuitkomst. Dit deelonderzoek levert inzicht in de betekenissen die door de beoordelaars aan aspecten van het vertelde verhaal en van de presentatie daarvan worden toegekend.

De betrouwbaarheid van deze procedure wordt vastgesteld door drie onderling onafhankelijke beoordelaars enkele protocollen voor te leggen en te laten segmenteren en interpreteren. De gevonden overeenstemming levert een maat voor de betrouwbaarheid van de dataverwerking (bijvoorbeeld via de eerder genoemde kappa van Fleiss).

Elk van deze episoden leggen we voor aan 30 beoordelaars: IND-medewerkers die beroepshalve bij de beoordeling van asielaanvragen betrokken zijn. Zij worden nadrukkelijk geïnstrueerd - en indien nodig ook enigermate getraind, om al te grote verschillen in de verbale capaciteiten van de beoordelaars te nivelleren - om hardop te verwoorden hoe zij de voorgelegde gespreksepisode interpreteren in het licht van de asielaanvraag. Object van aandacht is uiteraard datgene wat de asielaanvrager vertelt; maar is ook de wijze waarop hij zijn vluchtverhaal vertelt, met inbegrip van mimiek en lichaamstaal. In de beoogde onderzoeksopzet beoordeelt telkens een groep van 30 medewerkers de fragmenten van één van de twee opgenomen asielgesprekken. Het aantal van 30 beoordelaars per gesprek is gebaseerd op de verwachting dat dit aantal voldoende is om de beoogde informatie inhoudelijk te verzadigen (Baarda e.a., 1995, p. 83). Dat wil zeggen dat er dan geen nieuwe informatie of inzichten meer naar voren zullen komen.

3. Deze hardopdenk-sessies worden tezamen met de daar aangeboden videobeelden op video opgenomen. Dat maakt het mogelijk om de individuele protocollen nadrukkelijk te koppelen aan de voorgelegde gespreksfragmenten. Deze video-opnames leveren de protocollen die in het onderzoek geanalyseerd worden. Uiteindelijk komen langs deze weg dus als onderzoeksdata de protocollen van 2 × 30 hardopdenk-sessies beschikbaar, telkens verdeeld in becommentarieerde episoden. 


\subsection{Data-analyse}

Analyse van deze interpretatieketens moet allereerst een antwoord geven op de vraag welke cognitieve strategieën IND-medewerkers bij de interpretatie en beoordeling van asielverhalen hanteren; toegespitst op de vraag aan welke aspecten van het asielverhaal of van de presentatie daarvan zij relevante betekenis toekennen. Daarin kan het expliciet gaan om de invloed van non-verbale aspecten van gedrag maar ook om de verbale aspecten.

Vergelijking van deze interpretatieketens in de protocollen van de verschillende deelnemers moet een antwoord geven op de vraag of IND-medewerkers overwegend dezelfde interpretatiestrategieën hanteren, dan wel of zij daarin onderling in belangrijke mate verschillen. Een statistische analysetechniek die hierbij gebruikt kan worden, is de 'lag-sequentiële analyse' (Bakeman \& Gottman, 1997). Daarmee wordt getracht te achterhalen of bepaalde interpretatieketens 'boven-kans' voorkomen (vaker voorkomen dan op basis van toeval verwacht mag worden).

Tenslotte kan op basis van onderlinge vergelijking van interpretatieketens in de verschillende protocollen en met behulp van dezelfde statistische analysetechniek worden vastgesteld of IND-medewerkers tot dezelfde probleemoplossing komen, dan wel of zij daarin in belangrijke mate verschillen.

\subsection{Relevantie van het onderzoele}

De uitkomsten van dit onderzoek geven een betrouwbaar inzicht in de wijze waarop in een veelal interculturele situatie het verhaal van asielzoekers in de gehoorsituatie geïnterpreteerd en beoordeeld wordt en in het bijzonder op welke indicatoren de interpretatie en beoordeling gebaseerd wordt. Dit inzicht is een noodzakelijke voorwaarde voor het verfijnen van trainingsprogramma's waarmee beoordelaars van asielaanvragen voor hun taak worden opgeleid. We kiezen voorlopig niet voor een experimenteel design, waarin bijvoorbeeld dezelfde gespreksinhoud met diverse nonverbale gedragingen aan verschillende groepen van beoordelaars wordt aangeboden. Wellicht dat deelhypotheses in een onderwijssetting (doctoraalcolleges, scripties) experimenteel getoetst kunnen worden. Echter, wij stellen een observationeel design voor met gebruikmaking van de hardopdenk-procedure om de nu relevante onderzoeksvragen te beantwoorden.

Weliswaar wordt in dit onderzoek niet het feitelijke interpretatieproces van de betrokken IND-ambtenaar in de gehoorsituatie onderzocht; maar de onderzoeksresultaten mogen aanzienlijk betrouwbaarder geacht worden dan de data die verkregen zouden kunnen worden via interviews na afloop (zie Nisbett \& Wilson, 1977; zie ook Ericsson \& Simon, 1980 en 1993). Met een dergelijk vervolgonderzoek denken we een zinvolle bijdrage te leveren, zowel in onderzoeksmatige als in maatschappelijke zin, aan het verkrijgen van inzichten in de belangrijke rol die taal en communicatie vervullen in de beoordeling van asielaanvragen. 


\section{Bibliografie}

Baarda, D.B., Goede, M.P.M. de, \& Teunissen, J. (1995). Kwalitatief onderzoek. Praktische handleiding voor het opzetten en vitvoeren van kwalitatief onderzoek. Houten: Stenfert Kroese.

Bakeman, R., \& Gottman, R. (1997). Observing interaction: an introduction to sequential analysis (2nd ed.). Cambridge: Cambridge University Press.

Breuker, J.A., Elshout, J.J., Someren, M.W. van, \& Wielinga, B.J. (1986). Hardop denken en Protokolanalyse. Tijdschrift voor Onderwijsresearch, 11, 241-254.

DePaulo, B.M. (1988). Nonverbal aspects of deception. Journal of Nonverbal Behavior, 12, 153-161.

Ekman, P. (1988). Lying and nonverbal behavior: Theoretical issues and new findings. Journal of Nonverbal Behavior, 12, 163-175.

Ekman, P., \& Friesen, W.V. (1974). Nonverbal leakage and clues to deception. In S. Weitz (Ed.), Nonverbal communication. Readings with commentary (pp. 269-290). New York: Oxford University Press.

Ekman, P., O’Sullivan, M., Friesen, W.V., \& Scherer, K. (1991). Face, voice, and body in detecting deceit. Journal of Nonverbal Behavior, 15, 125-135.

Ericsson, K.A., \& Simon, H.A. (1980). Verbal reports as data. Psychological Review, 87, 215-251.

Ericsson, K. A., \& Simon, H.A. (1993). Protocol Analysis. Verbal reports as data (revised edition). Cambridge: Bradford.

Ferguson, G.A., \& Takana, Y. (1989). Statistical analysis in psychology and education (6th ed.). Singapore: McGraw-Hill.

Fleiss, J.L. (1971). Measuring nominal scale agreement among many raters. Psychological Bulletin, 76, 378-382.

Flower, L. (1989). Problem Solving Strategies for Writing. San Diego: Harcourt Brace Jovanovich.

Giesbers, H. (1999). Interculturele communicatie - Valkuilen en mogelijkheden. In M. Gerritsen \& D. Springorum (Red.), Een bundel Bedrijfscommunicatie voor Ger Peerbooms bij gelegenheid van zijn $65^{e}$ verjaardag (pp. 75-85). Nijmegen: Nijmegen University Press.

Groot, A.D. de, (1965). Thought and choice in chess. The Hague: Mouton.

Hayes, J.R., \& Flower, L. (1983). Uncovering cognitive processes in writing. An introduction to protocol analysis. In P. Mosenthal, L. Tamor \& S.A. Walmsley (Eds.), Research on writing. Principles and methods (pp.206-219). New York: Longman.

Hurley, D.S. (1992). Issues in teaching pragmatics, prosody, and non-verbal communication. Applied Linguistics, 13, 259-281.

Huls, E. (1995). Communicatiepatronen in Turkse gezinnen. In E. Huls \& J. KlatterFolmer (Red.), Artikelen van de Tweede Sociolinguïstische Conferentie (pp. 285-299). Delft: Eburon.

Janssens, J.M.A.M. (1988). Ogen doen onderzoek. Lissen/Amsterdam: Swets \& Zeitlinger.

Jong, M. de, \& Schellens, P.J. (1995). Met het oog op de lezer. Pretestmethoden voor schriftelijk voorlichtingsmateriaal. Amsterdam: Thesis Publishers.

Kalma, A., Witte, M., \& Zaalberg, R. (1996). Authenticity: operationalization, manipulation, and behavorial components: an exploteration. Medienpsychologie, 8, 4965.

Kellerman, S. (1992). 'I see what you mean': The role of kinesic behaviour in listening and implications for foreign and second language learning. Applied Linguistics, 13, 239-258. 
Koomen, W. (1988). Sociale perceptie. In R.W. Meertens \& J. von Grumbkow (Red.), Sociale Psychologie (pp. 77-92). Groningen: Wolters-Noordhoff.

Korzilius, H., \& Springorum, D. (1999). De betekenis van lichaamstaal in een gehoorsituatie. In E. Huls \& B. Weltens (Red.), Artikelen van de Derde Sociolinguïstische Conferentie (pp. 275-286). Delft: Eburon.

Maxwell, S.E., \& Delaney, H.D. (1990). Designing experiments and analyzing data. A model comparison perspective. Belmont, CA: Wadworth.

Nisbett, R.E., \& Wilson, T.D. (1977). Telling more than we can know: verbal reports on mental processes. Psychological Review, 84, 231-259.

Pennycook, S. (1985). Actions speak louder than words: Paralanguage, communication, and education. Tesol Quarterly, 19, 259-282.

Rietveld, T., \& Hout, R. van (1993). Statistical techniques for the study of languages and language behavior. Berlin: Mouton de Gruyter.

Vrij, A. (1991). Misverstanden tussen politie en allocbtonen: sociaal-psychologische aspecten van verdacht rijn. Amsterdam: VU Uitgeverij.

Vrij, A. (1992). Het maken van een verdachte indruk op rechercheurs. De invloed van stereotiepen, sociale vaardigheden, verbaal- en non-verbaal gedrag op de oordeelsvorming. Tijdschrift voor Criminologie, 34, 129-143.

Vrij, A. (1994). The impact of information and setting on detection of deception by police detectives. Journal of Nonverbal Behavior, 18, 117-136.

Vrij, A., \& Winkel, F.W. (1991). Cultural patterns in Dutch and Surinam nonverbal behavior: An analysis of simulated police/citizen encounters. Journal of Nonverbal Behavior, 15, 169-184.

Vrij, A., Foppes, J.H., Volger, D.M., \& Winkel, F.W. (1992). Moeilijk te bepalen wie de waarheid spreekt. Non-verbaal gedrag belangrijke indicator. Algemeen Politieblad, 141 (20), 13-14.

Vrugt, A., \& Schabracq, M. (1991). Vanzelfsprekend gedrag. Opstellen over nonverbale communicatie. Meppel: Boom. 